\title{
The Sub-acute Effect of Lead Exposure on the Auditory Brainstem Response in
}

\section{Male Rats}

\section{Iraj Alimohammadi 1(D), Azadeh Ashtarinezhad 1(D), Jamileh Abolghasemi 2(D), Parvaneh Yekzamani 1(D), Batol Masruri*1(D)}

1. Department of Occupational Health, Iran University of Medical Sciences. Tehran, Iran.

2. Department of Biostatistics, Iran University of Medical Sciences. Tehran, Iran.

\begin{tabular}{ll}
\hline Article Info & A B S T R A C T \\
\hline $\begin{array}{ll}\text { Article Type: } \\
\text { Original Research }\end{array}$ & Background: \\
\hline Article History: & Lead is a major environmental pollutant and can adversely affect humans \\
Received: 16.04 .2019 & and animals. There are conflicting data about the ototoxic effect of lead. \\
Accepted: 01.06 .2019 & This study experimentally examined the association between blood lead \\
& levels (BLL) and the subsequent hearing impairment in male rats.
\end{tabular}

\section{Methods:}

* Corresponding Author:

Batol Masruri

Department of Occupational Health,

Iran University of Medical Sciences.

Tehran, Iran

E-mail: batolmasruri@gmail.com
Twenty-two male rats were randomly categorized into experimental (exposed to lead acetate, $4 \mathrm{mg} / \mathrm{kg}$ by gavage) and control groups. We evaluated the groups by click and tone audiometric burst tests, comparing the data before and 30 days after exposure to lead acetate $(4 \mathrm{mg} / \mathrm{kg})$. Also, blood samples were collected from the rats and analyzed for lead levels by graphite furnace atomic absorption spectrometry.

Results:

The study findings demonstrated remarkable increase in hearing threshold in the lead-exposed group, compared to the controls $(\mathrm{p}<0.0001)$. Also, the blood lead levels revealed a significant association of lead acetate with the hearing loss in rats.

\section{Conclusion:}

This study revealed that exposure to lead acetate can be damaging to hearing. However, future research is recommended to clarify the mechanism of action of lead toxicity on the auditory function at varying blood lead concentrations.

Keywords:

Auditory Brainstem Response, Blood Lead Level, Hearing Loss, Lead Toxicity, Ototoxicity.

How to cite this paper

Alimohammadi I, Ashtarinezhad A, Abolghasemi J, Yekzamani P, Masruri B. The Sub-acute Effect of Lead Exposure on the Auditory Brainstem Response in Male Rats.Iran J Toxicol.2019; 13 (3):9-13

\section{INTRODUCTION}

Nowadays, work-induced hearing loss is one of the critical issues for the occupational health and safety experts. The U.S. National Institute for Occupational Safety and Health (NIOSH) has reported the workinduced hearing loss as one of the priority research areas in the $21^{\text {st }}$ century (1). Even though exposure to excessive levels of noise has been commonly considered as the principal hazard for hearing loss but increasing amounts of recent evidence have demonstrated that occupational hearing loss can be exacerbated by exposure to ototoxic substances (2). Such substances are widely used in various industries and are absorbed by the human body primarily via food chain, water and air ( $\underline{3})$. Toxic injury to the sensory or secretory epithelia of the labyrinth and the auditory nerve is termed "ototoxicity" (4). Examples of workrelated ototoxic agents are heavy metals (lead \& cadmium), noise, chemical solvents, such as toluene, xylene, styrene \& methyl ethyl ketone. Also, certain ototoxic drugs that are widely used include aminoglycoside antibiotics and chemotherapy drugs, such as cisplatin, carboplatin and oxaliplatin $(\underline{5,6})$. Among heavy metal, lead and cadmium are prevalent in the environment and are widely used in industries despite their toxicity (7). The physical properties of Lead such as flexibility, low chemical reactivity, high density, low cost and simple extraction may be reasons behind its extensive use (ㅁ). Lead exposure can occur from various sources such as fossil fuels, air pollution, plumbing system, paint and battery manufacturing 
plants, and printing houses (ㅁ). The main routes of toxicity from inorganic lead compounds are the respiratory and digestive systems while skin is the common route of entry into the body for organic lead compounds. Absorption of lead in children by ingestion is five times greater than that in adult particularly when there is mineral deficiency. Lead binds to erythrocytes in the blood and enters the soft tissues and bones (10). The half-life values of lead in the blood, soft tissue and bone are 30 days, 30-45 days and 25-30 years, respectively (11).

Lead is a cumulative poison and affects the bodily systems, including hematopoietic, renal, cardiovascular, reproductive and nervous systems. However, the most undesirable effect lead is on the nervous system. One of the common symptoms of lead toxicity is peripheral neuropathy, the common signs of it are "wrist drop" and "foot drop" in workers exposed to this heavy metal ( $\underline{12})$.

In auditory system, lead can decrease the evoked potentials and sensitivity by inducing demyelination and axonal disintegration in the auditory nervous system (13). In the central and peripheral auditory systems, evidence suggests that lead can affect both the afferent and efferent nerves, and cause damage to the sensory nerve endings within the peripheral nerves leading to the degeneration of cochlear receptor cells in the inner ear (14). The sensory receptors of the hearing system are hair cells and their loss results in hearing impairment and ultimately hearing loss.

Previous studies showed that lead exposure may be a risk factor to the auditory organ and lead to hearing loss $(\underline{15})$. Also, they indicated that neurological effects may take place at BLLs lower than $10 \mu \mathrm{g} / \mathrm{dL}(\underline{16})$. Contrary to these studies; some works demonstrated that there is no considerable relationship between damage to the hearing system and lead exposure (17). Due to the current conflicting findings, about the nature of lead-induced hearing loss, the aim of this study was to investigate the effects of lead on hearing loss in rats caused by subacute lead exposure.

\section{MATERIALS AND METHODS}

Study Design: 22 healthy Wistar male rats (weight 250-300 g), used for the experiments, were obtained from Experimental and Comparative studies center, Iran University of Medical Science, Tehran, Iran. The animals were fed common rat pellets and water, housed at $23 \pm 1^{\circ} \mathrm{C}$ and $40-50 \%$ relative humidity, and $12 \mathrm{~h}$ dark/light cycle. They were randomly divided into two equal groups. Group 1: Control rats were not exposed to lead); Group 2: Experimental rats were exposed by daily gavage to $4 \mathrm{mg} / \mathrm{kg}$ lead acetate dissolved in distilled water for 30 days. Lead acetate was purchased from Merck (Chemical Abstract Service [CAS]: 107375; Germany). All tests and experimental procedure were performed conforming to the ethical standards and guidelines approved by the Ethics Committee, Iran University of Medical Sciences (Approval \#: IR.IUMS.REC 1395.9413139004).
Auditory Brainstem Response: Hearing function was measured by auditory brainstem response (ABR) threshold test. Rats from the two groups were deeply anesthetized by a mixture of Ketamine (50-100 mg/kg) and Xylazine (5-10 mg/Kg) Intraperitoneally, and were kept warm, using a heating blanket. The ABR test was performed before and after exposure to lead acetate, and the difference between the ABR at baseline and that on the $30^{\text {th }}$ day was considered as the temporary threshold shift (TTS). The ABR from control rats was also measured. The test stimuli for both test were click and tone burst at $4000 \mathrm{~Hz}$ (5 msec. at 23.1 or 39.1 signal/sec), using an Interacoustics EP25 unit (Denmark). Subdermal electrodes were placed on the forehead and behind the right and left ears, with the ground electrode attached to the animal's hind leg. The sound stimuli were routed through an insert earphone fitted in the rat's ear canal. The test intensity began at $70 \mathrm{~dB}$ and was lowered to $20 \mathrm{~dB}$ in each step (near threshold), the stimulus intensity was decreased in 5 $\mathrm{dB}$ steps until the ABR waveform was obtained. Responses to 1024 tone presentations were amplified (x100000), filtered (150-1500 Hz) and averaged for each intensity level. ABR threshold was defined as the lowest intensity that produced a detectable ABR waveform (wave II).

Blood Lead Levels in Rats (BLL): Lead acetate levels in rats' blood were determined as its concentration in the whole blood according to NIOSH 8003. On the first and $30^{\text {th }}$ days after exposure to lead acetate, the rats in both groups were anesthetized with ketamine (50-100 mg/kg) and xylazine (10-5 mg / kg), blood samples were collected from the rats' heart and cast into EDTA containing test tubes. The blood lead levels were measured by Graphite Furnace Atomic Absorption spectrophotometer (GFAAS, GF5000, GBC; Australia). Prior to the spectrophotometry, $0.8 \mathrm{ml}$ APDC-TX100 is used. This solution is made as follows: dissolve $2 \mathrm{~g}$ APDC and $2.5 \mathrm{ml}$ TX-100 in deionized water, then dilute to $100 \mathrm{ml}$. Lead acetate $(.8 \mathrm{ml}$; CAS: 821100 and 112298, respectively, MERCK; Germany) was added to $2 \mathrm{ml}$ blood and were mixed for $10 \mathrm{sec}$. Then the mixture was added to $2 \mathrm{ml}$ MIBK (CAS: 820820, MERCK; Germany) and mixed for 2 min, centrifuged at $2000 \mathrm{rpm}$ for $10 \mathrm{~min}$ and analyzed by GFAA spectrophotometry.

Statistical Analyses: The statistical analyses were carried out using SPSS 22.0. The Kolmogorov-Smirnov test (K-S test) was used to determine the data normality for each group. Also, ANOVA (Bonferroni post-hoc) and paired $t$-tests were performed to compare the averaged data before and after the lead acetate exposure. Pearson's correlation coefficients were determined to evaluate the relation between BLL levels and the hearing thresholds. All data were expressed as mean $\pm \mathrm{SD}$, with the statistical significance at $P<0.05$.

\section{RESULT}

Blood Lead Levels: The outcome of the blood lead level determinations are presented in Table 1 . The 
differences between the blood lead levels for the experimental and control groups were statistically significant $(P<0.0001)$.

Table 1. Blood lead levels in the control and lead acetate exposed groups.

\begin{tabular}{cc}
\hline Group & Blood lead level $(\mu \mathrm{g} / \mathrm{dl})$ \\
\hline Control & $0.27 \pm 0.01$ \\
Lead Exposure & $2.89 \pm 0.2$
\end{tabular}

* Experimental group exposed to $4 \mathrm{mg} / \mathrm{kg}$ lead acetate by gavage. $\mathrm{N}=11$ rats per group. Values are means \pm SD.

Auditory Brainstem Response: The ABR threshold shift $(\mathrm{dB})$ with click and tone burst stimuli, before and after exposure, are shown in Figure 1. The relationship between BLL and hearing threshold are reflected in Figure 2. The means of ABR threshold before exposure in control and lead-exposed groups with click stimulus were 13-14 $\mathrm{dB}$, respectively. Also, the values for tone burst stimulus were 12 and $16.5 \mathrm{~dB}$, respectively, bearing an insignificant difference.

The ABR threshold with click stimulus after exposure indicated that the lead-exposed group had a considerable elevation compared to that for the control group ( $7 \mathrm{~dB}$ increase in hearing threshold, $P<0.0001$ ). Also, a significant enhancement $(16 \mathrm{~dB})$ was observed in ABR hearing threshold shift in the lead exposed group compared to that for the control group $(P<0.0001)$. However, a significant relationship was found between BLL and hearing threshold only with tone burst stimulus $(r=0.739, P \leq 0.015)$ and there was no statistically significant relationship between rats hearing impairment and BLL based on the click stimulus $(r=0.18, P \leq 0.618)$.
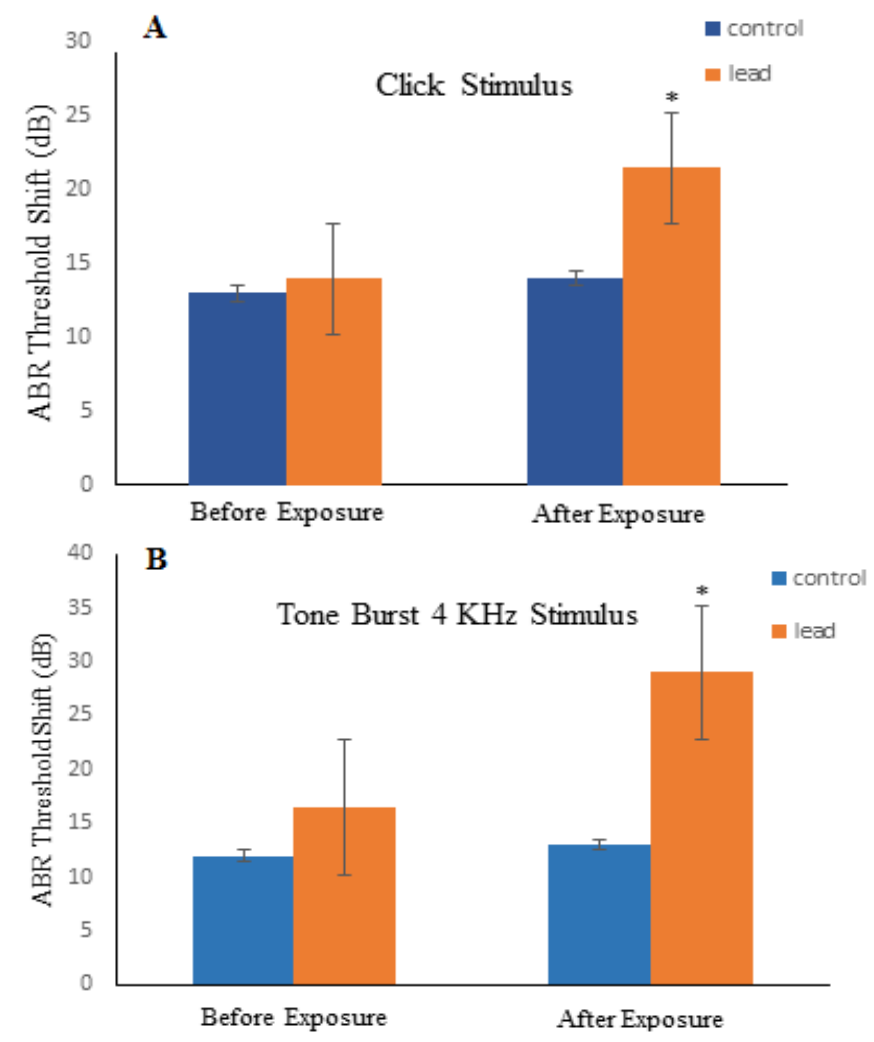

Figure 1. Effect of lead exposure on ABR threshold shifts (dB) in control and lead acetate $(4 \mathrm{mg} / \mathrm{kg})$ exposed groups with click (A) and tone burst (B) stimuli. * $P<0.0001$ compared with the control group. Data are shown as mean $\pm \mathrm{SD}(\mathrm{N}=11)$.
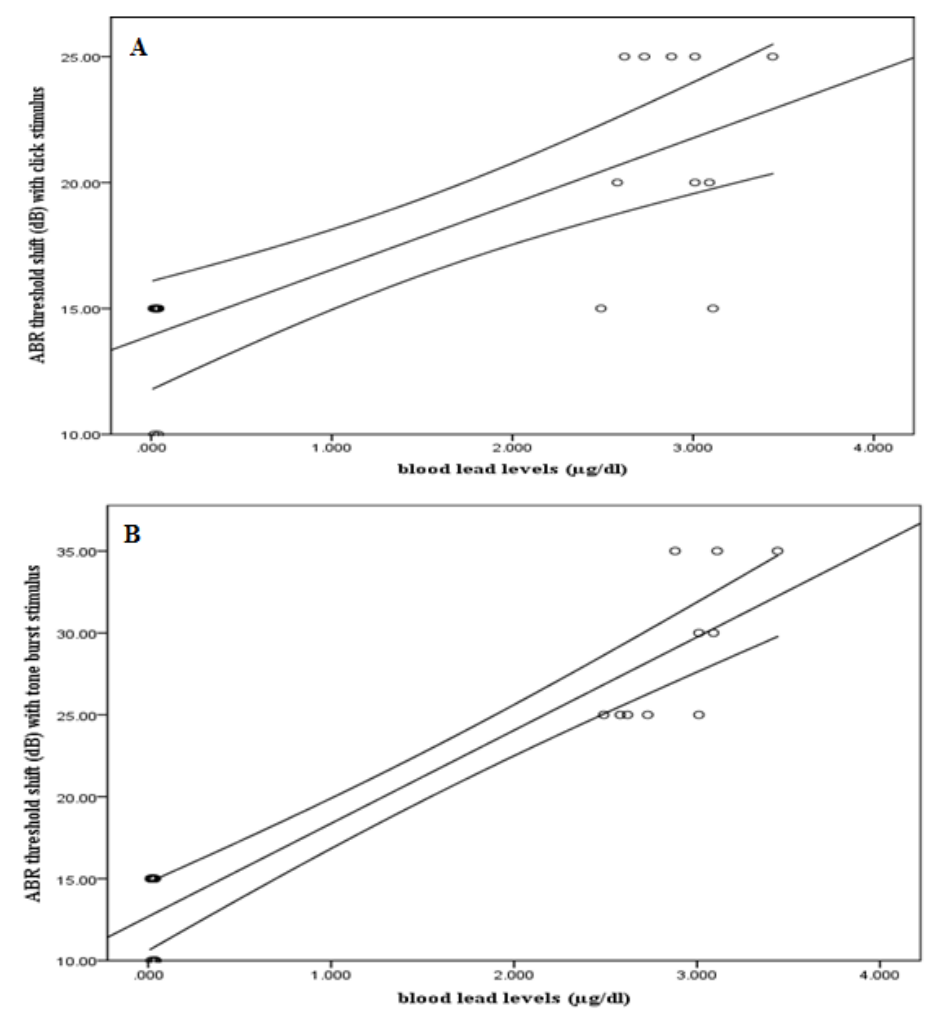

Figure 2. Correlation of average blood lead levels and hearing thresholds with: A) Click stimulus ( $\mathrm{r}=0.18, \mathrm{p}=0.618)$ and, $\mathrm{B})$ Tone burst stimulus $(r=0.739 ; P \leq 0.015)$. Both graphs show regression lines at the 95\% confidence interval and plotted, using SPSS v.22.

\section{DISCUSSION}

Heavy metals are toxic and are widely used in various industries. They are capable of causing physiological, biochemical and histological disturbances (18). In this context, the assessment of the toxic potential of these metals is crucial for people in the industries that are exposed to them (19). Lead is one of the toxic heavy metals to which people are exposed from a multitude of sources, such as mining, agriculture, plumbing, and paints, to name a few. Lead is on the federal Environmental Protection Agency's National Emission Standards for Hazardous Air Pollutants (NESHAP) list, among 187 other hazardous air pollutants. Also, it is listed as one of 30 most hazardous air pollutants that poses the greatest threat to public health in urban areas (20). Short-term exposure to lead can cause damage to brain, kidney and gastrointestinal tract, while the long-term exposure can induce adverse effects on the blood, central nervous system, hearing and cardiovascular systems (1ㅡ).

In the present study, we examined the adverse effects of sub-acute lead exposure on the auditory brainstem response in male rats. Our results demonstrated that there was an increased hearing impairment to $4000 \mathrm{~Hz}$ frequency following sub-acute exposure to lead with both click and tone burst stimuli (Fig. 1). Our results

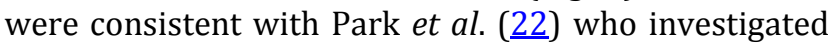
the association of age-related hearing loss with chronic and cumulative exposure to lead. They found that lead exposure was associated with changes in hearing threshold particularly in the frequency range of 4000 $\mathrm{Hz}$ (22). Likewise, Liu et al. studied the sub-acute effect 
of lead exposure at $4 \mathrm{mg} / \mathrm{kg}$ for 30 days and documented similar results $(\underline{23})$. Consistent results were also found by Schwartz and Otto (24) who reported an association between blood lead level and hearing threshold at all tested frequencies $(0.5,1,2,4$ $\mathrm{KHz}$ ) (24). A study conducted by Liu et al. (15) on rats and guinea pigs that were exposed to $300 \mathrm{ppm}$ lead acetate for 8 weeks and $50 \mathrm{mg} / \mathrm{Kg}$ lead acetate by intraperitoneal injection twice a week for 8 weeks, respectively. These authors reported a remarkable increase in the animals' ABR threshold and evidence of damage to the outer hair cells (15). Auditory hair cells in the mammalian cochlea have notable sensitivity in detecting noises, and damage to them is the major cause of sensorineural hearing loss (15). Some studies have suggested that ototoxic substances are likely to target the auditory system, causing loss of outer and inner hair cells ; however, the mechanism of leadinduced hearing loss is uncertain (25).

Other animal studies have reported contradictory results on the effects of lead on hearing. In monkeys, BLLs of $35 \mu \mathrm{g} / \mathrm{dl}$ following long-term exposure to lead did not cause notable effects on the brain stem auditory evoked potentials (26). In another study, dysfunction of the $8^{\text {th }}$ cranial nerve in guinea pigs was induced following a high dosage of lead exposure for 1-5 weeks. This level of exposure; however, did not produce the electrophysiological evidence of dysfunction in the organ of Corti and the Stria vascularis (27). By contrast, one study in rats showed that sub-acute exposure to 4 $\mathrm{mg} / \mathrm{kg}$ lead acetate for 30 days caused hearing loss through cochlear damage (26).

Results of the present study revealed that there was a significant relationship between hearing threshold and blood lead levels as detected by tone burst stimulus ( $r$ $=0.739, P \leq 0.015$ ) but there was no relationship between blood lead levels and hearing threshold as tested with click stimulus (Fig. 2). Hence, contrary to previous studies (르), the findings of the present investigation suggest that lead has definite ototoxic effects in the tested animals. Also, the findings reported by Choi and Wu were consistent with our results (29).

One study has suggested that the mechanism of lead neurotoxicity might be due to multiple effects at different sites, such as lipid peroxidation, impairment of neurotransmitter storage and release, changes in the expression and function of receptors, impaired mitochondrial and second-messengers interactions, and damage to the astroglia and oligodendroglia ( $\underline{30})$. An underlying factor accounting for lead toxicity is believed to be its ability to replace for calcium at receptor sites or within the cell $(\underline{31})$. A recent study has demonstrated that inorganic $\mathrm{Pb}^{+2}$ can be replaced with some intracellular $\mathrm{Ca}^{+2}$ binding proteins. The lead communication and dependency with calmodulin is greater than those with calcium $(\underline{32})$. With regards to the stereocilia bundles, both the outer and inner hair cells in the inner ear are essential components of the auditory circuitry ( $\underline{33})$. Therefore, derangement in their activity may be marked as hearing loss, through mutations of the structural proteins that begin and adjust the mechano-electrical transduction process. The important components of the process are Cadherin 23 and plasma membrane calcium ATPase isoform 2 (PMCA2) that are responsible for rejecting $\mathrm{Ca}^{+2}$ from the OHCs stereocilia. Calcium balance in the hair cells and in the endolymph has a critical role in the hearing process ( $\underline{34})$. The outcomes of mutations in plasma membrane calcium ATPase (PMCA) in humans and mice along with the concurrent mutations of Cadherin 23 have been shown to impair the ejection of $\mathrm{Ca} 2+$ from hair cells, ultimately causing deafness. It seems that lead, through replacement with calcium, can cause mutations in PMCA2 and Cadherin 23, and lead to hearing impairment. Thus, these are some of strong hypotheses in support of lead toxicity and auditory brainstem lesions, particularly in both chronic and acute low-level exposure models of lead neurotoxicity (프).

Limitations of the Study: A limitation of this study was that it only examined auditory brainstem responses at one dose of lead acetate. Therefore, the acute findings of this study may not be generalized to other nervous system responses, especially in the longterm. Elucidation of these effects awaits further investigations.

\section{CONCLUSION}

The findings of this study demonstrated that sub-acute exposure to lead induces hearing disorder in male rats. Hence, it is suggested that the presence of lead at work environment or if ingested through contaminated foods can adversely impact humans, particularly causing auditory impairment and ultimately deafness. Further studies are required to clarify the effects of various concentrations of lead and the molecular mechanisms by which it adversely affects the auditory system.

\section{ACKNOWLEDGMENTS}

This article was part of a M.Sc. thesis funded by Iran University of Medical Sciences (Grant No: 29407). Authors are grateful to the Toxicology Laboratory, School of Public Health and Experimental and Comparative Studies Center, at Iran University of Medical Sciences for cooperation and providing the facilities to conduct this project. Also, we appreciate the School of Public Health at Tarbiat Modares University, Tehran, Iran, for their collaboration with us in conducting the ABR tests.

\section{CONFLICT OF INTEREST}

The authors declare no conflict of interest in conducting this research.

\section{REFERENCES}

1. CDC (2001) Work Related Hearing Loss. Atlanta GCfDCaP.

2. Schaal N, Slagley J, Zreiqat M, Paschold H. Effects of combined exposure to metals, solvents, and noise on permanent threshold shifts. American journal of industrial medicine. 2017;60(3):227-38.

3. Choi Y-H, Kim K. Noise-induced hearing loss in Korean workers: co-exposure to organic solvents and heavy 
metals in nationwide industries. PloS one. 2014;9(5):e97538.

4. EU-OSHA European Agency for Safety and Health at Work, Combined exposure to noise and ototoxic substances, Luxembourg.

5. Choi Y-H, Hu H, Mukherjee B, Miller J, Park SK. Environmental cadmium and lead exposures and hearing loss in US adults: the National Health and Nutrition Examination Survey, 1999 to 2004. Environmental health perspectives. 2012;120(11):1544.

6. https://www.cancercenter.com/discussions/blog/hearingloss-the-little-known-side-effect-of-some-chemotherapydrugs/.

7. Haryanto B. Lead exposure from battery recycling in Indonesia. Reviews on environmental health. 2016;31(1):13-6.

8. Mortada WI, Sobh MA, El-Defrawy MM. The exposure to cadmium, lead and mercury from smoking and its impact on renal integrity. Medical Science Monitor. 2004;10(3):CR112-CR6.

9. Zahra N, Kalim I, Mahmood M, Naeem N. Perilous effects of heavy metals contamination on human health. Pakistan Journal of Analytical \& Environmental Chemistry. 2017;18(1):1.

10.https://www.cdc.gov/biomonitoring/Lead_Biomonitoring Summary.html.

11.http://www.health.state.mn.us/divs/fh/mch/webcourse/ lead/part1_3.cfm (Lead Poisoning in Children: Early Detection IaPPIDaE.

12. ATSDR, Toxicological Profile for Lead, Washington DC.

13. Zhao S, Ma Y, Ni L, Zhang J, Zhang T, Gao Y, et al. Study on effect of lead exposure to blood lead level and hearing in young offspring through gestation-rat. Lin chuang er bi yan hou ke za zhi= Journal of clinical otorhinolaryngology. 2006;20(4):172-3.

14. Lurie DI, Brooks DM, Gray LC. The effect of lead on the avian auditory brainstem. Neurotoxicology. 2006;27(1):108-17.

15. Liu X, Zheng G, Wu Y, Shen X, Jing J, Yu T, et al. Lead exposure results in hearing loss and disruption of the cochlear blood-labyrinth barrier and the protective role of iron supplement. Neurotoxicology. 2013;39:173-81.

16. Canfield RL, Henderson CR, Cory-Slechta DA, Cox C, Jusko TA, Lanphear BP. Intellectual impairment in children with blood lead concentrations below $10 \mu \mathrm{g}$ per deciliter. New England journal of medicine. 2003;348(16):151726.

17. Furness DN. Molecular basis of hair cell loss. Cell and tissue research. 2015;361(1):387-99.

18. Apaydin FG, Kalender S, Bas H, Demir F, Kalender Y. Lead nitrate induced testicular toxicity in diabetic and nondiabetic rats: protective role of sodium selenite. Brazilian Archives of Biology and Technology. 2015;58(1):68-74.

19. Al-Attar AM. Antioxidant effect of vitamin E treatment on some heavy metals-induced renal and testicular injuries in male mice. Saudi journal of biological sciences. 2011;18(1):63-72.

20. https://www.epa.gov/haps/initial-list-hazardous-airpollutants-modifications.

21. Simões MR, Preti SC, Azevedo BF, Fiorim J, Freire DD, Covre EP, et al. Low-level chronic lead exposure impairs neural control of blood pressure and heart rate in rats. Cardiovascular toxicology. 2017;17(2):190-9.

22. Park SK, Elmarsafawy S, Mukherjee B, Spiro III A, Vokonas $\mathrm{PS}$, Nie $\mathrm{H}$, et al. Cumulative lead exposure and age-related hearing loss: the VA Normative Aging Study. Hearing research. 2010;269(1-2):48-55.

23. Liu S, Zhang K, Wu S, Ji X, Li N, Liu R, et al. Lead-induced hearing loss in rats and the protective effect of copper. Biological trace element research. 2011;144(1-3):11129.

24. Schwartz J, Otto D. Blood lead, hearing thresholds, and neurobehavioral development in children and youth. Archives of Environmental Health: An International Journal. 1987;42(3):153-60.

25. Roth JA, Salvi R. Ototoxicity of Divalent Metals. Neurotoxicity research. 2016;30(2):268-82.

26. Lilienthal $\mathrm{H}$, Winneke G. Lead effects on the brain stem auditory evoked potential in monkeys during and after the treatment phase. Neurotoxicology and teratology. 1996;18(1):17-32.

27. Yamamura K, Terayama K, Yamamoto N, Kohyama A, Kishi R. Effects of acute lead acetate exposure on adult guinea pigs: electrophysiological study of the inner ear. Fundamental and Applied Toxicology. 1989;13(3):50915.

28. Buchanan LH. Distortion product oto-acoustic emissions in Andean children and adults with chronic lead intoxication. Acta oto-laryngologica. 1999;119(6):652-8.

29. Wu T-N, Shen C-Y, Lai J-S, Goo C-F, Ko K-N, Chi H-Y, et al. Effects of lead and noise exposures on hearing ability. Archives of Environmental Health: An International Journal. 2000;55(2):109-14.

30. Garza A, Vega R, Soto E. Cellular mechanisms of lead neurotoxicity. Medical science monitor. 2006;12(3):RA57-RA65.

31. Bradbury M, Deane R. Permeability of the blood-brain barrier to lead. Neurotoxicology. 1993;14(2-3):131-6.

32. Martines F, Maira E, Ferrara S. Age-related hearing impairment (ARHI): a common sensory deficit in the elderly. Acta Medica Mediterranea. 2011;27(1):47-52.

33. Schwander M, Kachar B, Müller U. The cell biology of hearing. The Journal of cell biology. 2010;190(1):9-20

34. Giacomello M, De Mario A, Primerano S, Brini M, Carafoli E. Hair cells, plasma membrane $\mathrm{Ca} 2+$ ATPase and deafness. The international journal of biochemistry \& cell biology. 2012;44(5):679-83.

35. Counter SA, Buchanan LH, Ortega F, Laurell G. Normal auditory brainstem and cochlear function in extreme pediatric plumbism. Journal of the neurological sciences. 1997;152(1):85-92. 